\title{
KEANEKARAGAMAN JENIS MAMALIA DIURNAL DI BEBERAPA TIPE HUTAN PADA AREAL IUPHHK-HT PT. HUTAN KETAPANG INDUSTRI KABUPATEN KETAPANG
}

\author{
(Species diversity of diurnal mammals in several habitat types in PT. Hutan Ketapang Industri
} Ketapang Regency)

\author{
Reno Manggala Putra, Erianto, Iswan Dewantara \\ Fakultas Kehutanan Universitas Tanjungpura, Jalan Imam Bonjol Pontianak, 78124 \\ Email: renomanggala28@gmail.com
}

\begin{abstract}
Mammals are wild animals that are often considered as pests by the community, even though the existence of mammals has an important role in the preservation of forest ecosystem as soil fertilizers, pollinators, seed dispersers, and biological bugs control. Forest is habitat for flora and fauna, but now the forests in Kalimantan are starting to be degraded caused by land clearing of plantations, illegal logging and infrastructure development. Forest degradation is very influential on forest cover, especially mammals. Land clearing by plantation companies has an impact on the survival of animals and vegetation in the plantation area. Food sources and shelter for mammals is reduced. That makes mammals move to habitats that are good vegetation and ecosystems. This study aims to record the diurnal mammal species and find out the diversity of species of mammals diumal in several forest types in the IUPHHK-HT area of PT. Hutan Ketapang Industri district Ketapang. This research was conducted on 25 February 2019 until 23 March 2019 to obtain data on species of mammals diumal in a number of forest types in the IUPHHK-HT area of PT. Hutan Ketapang Industri district Ketapang. The results of this study are expected to provide data and information on the types of diurnal mammals and the diversity of diurnal mammal species in several forest types in the IUPHHK-HT area of PT. Hutan Ketapang Industri district Ketapang The results of observations in five habitat types were found as many as 8 species belonging to 6 families. In Kerangas forest 2 species were found with 7 individuals, Peat Swamp forest was found 5 species with 15 individuals, Lowland Dipterocarpa forest was found 7 species with 19 individuals, Riparian forest was found 3 species with 9 individuals. and Open Wetlands / Flood Plains are found 3 species with a number of individuals 11.
\end{abstract}

Keywords: Mammals Diumal, Diversity, Five Habitat Types

\section{PENDAHULUAN}

Mamalia merupakan kelas vertebrata (bertulang belakang) yang memiliki kelenjar susu yang digunakan untuk menyusui anaknya. Mamalia berasal dari bahasa latin yaitu mammae berarti susu. Berdasarkan ukurannya, mamalia dibagi menjadi mamalia kecil dan mamalia besar. Menurut batasan International
Biological Program, yang dimaksud dengan mamalia kecil adalah jenis mamalia yang memiliki berat badan dewasa yang kurang dari lima kilogram, sedangkan selebihnya termasuk ke dalam kelompok mamalia besar. Setiap jenis mamalia memiliki daerah penyebaran tertentu berdasarkan kondisi geografis dan ekologis, penyebaran jenis mamalia 
berdasarkan faktor ekologi dapat diketahui melalui komposisi vegetasi suatu tipe habitat.

Mamalia merupakan salah satu komponen biotik selain memiliki dampak positif mamalia juga mempunyai dampak negatif bagi para petani, perkebunan, dan perusahaan sebagai contoh perusahaan yang bergerak di bidang hutan tanaman. Beberapa mamalia sering dianggap sebagai hama karena dapat menimbulkan kerugian seperti merusak lahan pertanian dan bibit tanaman, disamping memiliki dampak negatif mamalia juga memiliki dampak positif seperti menyebarkan biji, dan membantu penyerbukan bunga.

PT. Hutan Ketapang Industri merupakan perusahaan swasta nasional yang bergerak di bidang pengusahaan Hutan Tanaman Industri (HTI) yang berlokasi di Kabupaten Ketapang, Provinsi Kalimantan Barat dengan luas \pm 100.150 ha. Seiring berjalannya kegiatan operasional perusahaan hutan di wilayah PT. Hutan Ketapang Indsutri mulai mengalami degradasi hutan yang disebabkan oleh pembukaan lahan perkebunan, penebangan secara ilegal dan pembangunan infrastruktur. Degradasi hutan sangat berpengaruh terhadap tutupan hutan terutama mamalia yang menghabiskan waktunya hidup di pepohonan (arboreal). Pembukaan lahan untuk kepentingan suatu perusahaan perkebunan sangat berdampak bagi kelangsungan hidup satwa dan vegetasi yang ada di areal perkebunan, sumber makanan bagi mamalia dan tempat tinggal bagi mamalia berkurang sehingga mamalia berpindah ke habitat yang masih terjaga ekosistemnya. Hal ini diperlukan penelitian tentang keanekaragaman jenis mamalia diurnal di beberapa tipe hutan pada areal IUPHHK-HT PT. Hutan Ketapang Industri Kabupaten Ketapang. Tujuan penelitian ini untuk mendapatkan data jenis mamalia diurnal di beberapa tipe hutan pada areal IUPHHK-HT PT. Hutan Ketapang Industri dan juga Mengetahui keanekaragaman jenis mamalia diurnal di beberapa tipe hutan pada areal IUPHHK-HT PT. Hutan Ketapang Industri.

\section{METODE PENELITIAN}

Penelitian ini dilakukan di lima tipe hutan pada kawasan PT. Ketapang Industri Kabupaten Ketapang. Alat yang digunakan yaitu Binokuler (teropong), buku identifikasi mamalia, kamera, GPS, tally sheet, alat tulis dan jam tangan. Objek penelitian ini adalah satwa liar mamalia yang di jumpai di beberapa tipe hutan pada areal IUPHHK-HT PT. Hutan Kettapang Industri.

Pengamatan dilakukan secara langsung dan tidak langsung (kotoran, jejak, dan suara). Pengamatan langsung menggunakan metode jalur transek yang ditempatkan secara purposive dan metode Point count. Penelitian ini menggunakan 1 jalur transek yang digunakan pada 5 tipe hutan yaitu hutan dipterocarpaceae (dataran rendah), hutan rawa gambut, hutan lahan basah / dataran terbuka, hutan kerangas, hutan 
riparian. Setiap jalur dengan panjang rata-rata $1.500 \mathrm{~m}$ dengan radius pengamatan untuk setiap titik sejauh 25 m ke kiri dan 25 meter ke kanan dengan jarak antar titik 300 meter waktu pengamatan 20 menit. Pelaksanaan pengamatan dilakukan dengan cara diam pada titik tertentu kemudian berjalan lagi dan berhenti dititik tertentu lagi lalu mencatat perjumpaan terhadap mamalia dalam rentan waktu tertentu dan luas tertentu.

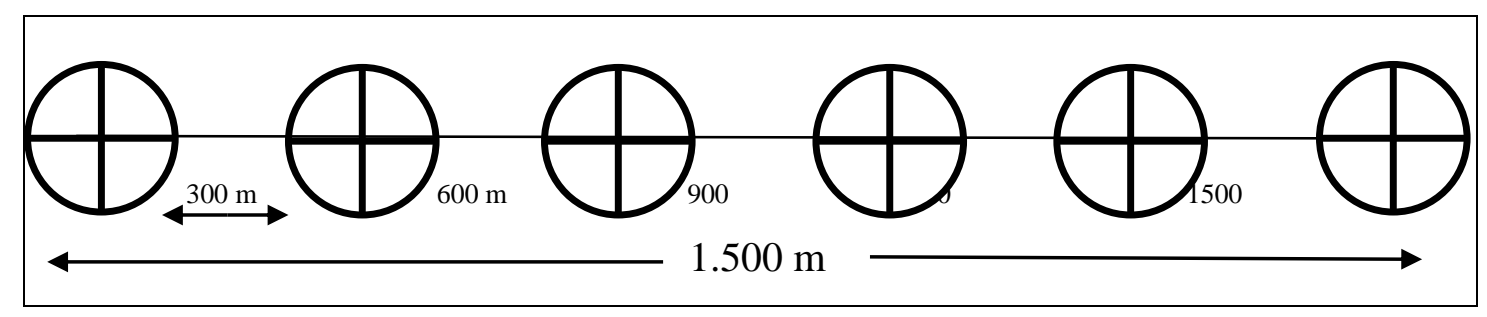

Gambar 1. Jalur pengamatan (line of observation)

\section{Analisis Data}

Analisis data

dilakukan

$n_{i}=$ Jumlah individu suatu spesies

menggunakan rumus menurut Odum

(1983 : 179), yaitu:

1. Kepadatan spesies

$\mathrm{Pi}=\frac{n_{i}}{H}$

Dimana :

$\mathrm{ni}=$ kepadatan spesies

$\mathrm{H}=$ total spesies

Dengan kriteria :

Padat $=75 \%$

Sedang $=2-5 \%$

Rendah $=0-<2 \%$

2. Indeks Dominasi (Simpson's Index) /

(Di)

$$
\mathrm{C}=-\sum \underset{\mathrm{i}=1}{\mathrm{~S}}
$$

Dimana:

$\mathrm{C}=$ Indeks Dominasi

$\mathrm{N}=$ Jumlah total individu
3. Indeks Keanekaragaman Shannon

(Shannon - Wienner Index) $/(\bar{H})$

$\bar{H}=-\sum\left(\frac{n i}{N}\right) \log \left(\frac{n i}{N}\right)$

Dimana :

$\bar{H}=$ Indeks Keanekaragaman

Shannon - Wiener

$\mathrm{Pi}=n \mathrm{i} / \mathrm{N}$

$\mathrm{N}=$ Jumlah Individu seluruh jenis

ni $=$ Jumlah individu suatu jenis

\section{Indeks Kemerataan (Pielou's}

Evenness Index) / (e)

$\mathrm{e}=\frac{\bar{H}}{\log S}$

Dimana :

e $\quad=$ Indeks kemerataan

$\overline{\mathrm{H}} \quad=$ Indeks Keanekaragaman

Shannon - Wiener
Waktu pengamatan disesuaikan dengan waktu aktifitas satwa pagi hari pukul 05.30- 08.30, sore hari pada pukul 15.00 - 17.30 WIB, dengan pengamatan satu kali pengulangan. Pengamatan dilakukan di sepanjang jalur transek, mamalia yang terlihat diidentifikasi dengan memperhatikan warna, bentuk, dan ukuran, serta ciriciri lainnya dengan menggunakan buku panduan lapangan. 
$\mathrm{S} \quad=$ Total jumlah spesies

5. Indeks Kekayaan Jenis (Species

Richness Index) / (d)

$d=\frac{S-1}{\log N}$

Dimana :

$\mathrm{d}=$ Indeks kekayaan jenis

$\mathrm{S}=$ Total Jumlah spesies

$\mathrm{N}=$ Total Jumlah individu seluruh jenis

6. Indeks Kesamaan Jenis (Similarity

$$
\text { Index) /(IS) }
$$

IS $=\frac{2 c}{a+b} \times 100 \%$

Dimana :

$I S=$ Indeks Kesamaan Jenis

$\mathrm{A}=$ Jumlah spesies yang diperoleh pada

tipe habitat 1

$\mathrm{B}=$ Jumlah spesies yang diperoleh pada

tipe habitat 2

$\mathrm{C}=$ Jumlah spesies yang sama pada

kedua habitat

\section{HASIL DAN PEMBAHASAN}

\section{Jumlah Jenis Mamalia Diurnal Pada Masing-masing Habitat}

Berdasarkan hasil pengamatan mamalia diurnal yang dilakukan di lima tipe habitat pada areal IUPHHK-HT PT. Hutan Ketapang Industri Kecamatan Kendawangan Kabupaten Ketapang memiliki jenis-jenis yang bervariasi di setiap habitatnya. Berdasarkan hasil pengamatan diketahui bahwa jumlah mamalia diurnal yang berhasil diamati sebanyak 5 ordo, 6 famili, dan 8 spesies yang terdiri dari 61 individu. Jenis mamalia diurnal pada setiap habitat dari setiap pegamatan diperoleh hasil yang berbeda antara suatu habitat dengan habitat lainnya.

Tabel 1. Rekapitulasi Jumlah Jenis dan Individu Mamalia Diurnal Pada Lima Tipe Hutan (Recapitulation of Diurnal mammals species and individuals in five forest types)

\begin{tabular}{|c|c|c|c|c|c|c|c|}
\hline No & $\begin{array}{c}\text { Jenis } \\
\text { Mamalia }\end{array}$ & Dipterocarpa & $\begin{array}{c}\text { Rawa } \\
\text { gambut }\end{array}$ & Kerangas & $\begin{array}{c}\text { Lahan } \\
\text { basah/dataran } \\
\text { terbuka }\end{array}$ & Riaparian & Jumlah \\
\hline \multirow[t]{2}{*}{1} & Bajing & & & & & & \\
\hline & Kelapa & 5 & 3 & 6 & 3 & 4 & 21 \\
\hline 2 & Tupai Akar & 2 & 5 & 2 & 4 & 3 & 16 \\
\hline 3 & Kelempiau & 4 & 3 & 3 & - & - & 10 \\
\hline 4 & Beruk & 2 & - & - & - & - & 2 \\
\hline 5 & $\begin{array}{l}\text { Monyet ekor } \\
\text { panjang }\end{array}$ & 3 & 2 & - & - & - & 5 \\
\hline 6 & Babi Hutan & 2 & - & - & - & 2 & 4 \\
\hline 7 & Kijang & 1 & - & - & - & - & 1 \\
\hline \multirow[t]{2}{*}{8} & Musang akar & _ & 2 & - & - & - & 2 \\
\hline & Jumlah & 19 & 15 & 11 & 7 & 9 & 61 \\
\hline
\end{tabular}


Tabel 2. Indeks Dominasi, Indeks Kekayaan, Indeks Keanekaragaman, dan Indeks Kemerataan mamalia diurnal yang dijumpai pada lima tipe hutan (Dominance index, Richess index, diversity index, evenness index of diurnal mammals species found in five forest types)

\begin{tabular}{lcccc}
\hline \multicolumn{1}{c}{ Lokasi Pengamatan } & $\begin{array}{c}\text { Indeks } \\
\text { Dominasi } \\
(\mathrm{Di})\end{array}$ & $\begin{array}{c}\text { Indeks } \\
\text { Keanekaragaman } \\
(\overline{\mathbf{H}})\end{array}$ & $\begin{array}{c}\text { Indek } \\
\text { Kemerataan } \\
(\mathrm{e})\end{array}$ & $\begin{array}{c}\text { Indeks } \\
\text { Kekayaan } \\
(\mathrm{d})\end{array}$ \\
\hline $\begin{array}{l}\text { Hutan Dipterocarpaceae } \\
\text { Hutan Rawa Gambut }\end{array}$ & 0,17 & 0,79 & 0,94 & 9,38 \\
Hutan Lahan & 0,22 & 0,67 & 0,96 & 8,50 \\
Basah/Dataran Terbuka & 0,40 & 0,43 & 0,90 & 7,68 \\
Kerangas & 0,51 & 0,29 & 0,98 & 5,91 \\
Riparian & 0,35 & 0,38 & 0,80 & 6,28 \\
\hline
\end{tabular}

Menurut (Ferianita, 2007) kisaran indeks dominan adalah 0-1 apabila nilai $\mathrm{Di}=0$ maka tidak terdapat spesies yang mendominasi spesies yang lain atau struktur komunitas labil, karena tekanan ekologis. Nilai indeks dominasi (Di) pada tipe hutan hutan dipterocarpaceae dataran rendah adalah $=0,17$. Indeks dominasi pada hutan rawa gambut $=0,22$. Indeks dominasi pada hutan lahan basah/dataran terbuka $=0,40$. Indeks dominasi pada hutan kerangas $=0,51$. Indeks dominasi pada hutan riparian $=0,35$. Berdasarkan hasil perhitungan Indeks dominasi (Di) jenis mamalia, diketahui bahwa pada tiap tipe habitat kerangas dengan nilai $\mathrm{Di}=$ 0,51. Hal ini dikarenakan jalur pengamatan pada tipe hutan kerangas hanya ditemukan 2 jenis mamalia serta sumber pakan pada hutan kerangas sangat cocok untuk kedua jenis tersebut dan berhubungan erat dengan kelimpahan yang tinggi.

Indeks keanekaragaman jenis digunakan untuk mengetahui keanekaragaman jenis makhluk hidup. Indeks ini menunjukkan besarnya variasi jenis di suatu tempat, sedangkan indeks kekayaan jenis merupakan nilai atau rasio perbandingan jenis antara jumlah jenis secara keseluruhan terhadap jumlah individu jenis yang dijumpai. kekayaan jenis sangat erat hubungannya dengan keanekaragaman jenis. Apabila keanekaragaman jenis di suatu lokasi tinggi maka kekayaan jenis juga tinggi. Akan tetapi keanekaragaman jenis berbanding terbalik dengan dominasi.

Jika pada suatu kawasan terjadi peningkatan keanekaragaman jenis maka akan terjadi penurunan dominasi oleh salah satu jenis atau kelompok kecil jenis tertentu. Menurut (Ferianita, 2007), kisaran keanekaragaman jens $(\bar{H})$ antara 13. Kisaran nilai $(\bar{H})<1$ berarti keanekaragaman jenis rendah, 1 - 3 berarti keanekaragaman sedang dan jika > 3 berarti keanekaragaman tinggi. Berdasarkan analisa data diketahui bahwa nilai indeks keanekaragaman jenis pada hutan dipterocarpaceae yaitu sebesar $(\bar{H})=$ 0,79 , hutan rawa gambut $(\bar{H})=0,67$, hutan lahan basah terbuka/dataran terbuka $(\bar{H})=$ 0,43, hutan kerangas $(\bar{H})=0,29$, hutan riparian $(\bar{H})=0,38$. Analisa data diketahui bahwa indeks keanekaragaman jenis pada habitat hutan dipterocarpa yang paling tinggi $(\bar{H})=0,29$. Hal ini dikarenakan 
pada jalur pengamatan tersebut masih vegetasi yang lebat, tipe hutan tersebut lebih banyak menyediakan makanan dan tempat berlindung bagi mamalia didalam kawasan tersebut.

Indeks kekayaan (d) jenis pada habitat hutan dipterocarpa yaitu sebesar $(\bar{H})=$ 9,38 , hutan rawa gambut $(\mathrm{d})=8,50$, hutan lahan basah terbuka/dataran banjir (d) = 7,68, hutan kerangas 5,91, hutan riparian yaitu sebesar $(d)=6,28$. Nilai indeks yang paling tinggi yaitu hutan dipterocarpaceae sebesar $(d)=9,38$ dan yang terendah yaitu hutan kerangas yaitu sebesar (d) $=5,91$. Tinggi dan rendahnya nilai indeks keanekaragaman dan indeks kekayaan jenis pada kelima hutan ini dikarenakan kondisi vegetasi yang tumbuh pada kelima habitat tersebut sangat bervariasi. Bervariasinya jumlah vegetasi yang tumbuh pada suatu lokasi mengakibatkan jumlah makanan menjadi berlimpah sehingga dapat mendukung bagi perkembangan mamalia diurnal. Adanya perbedaan jenis dan jumlah mamalia diurnal yang teramati pada setiap lokasi pengamatan menunjukkan bahwa mamalia memiliki toleransi yang tinggi terhadap keadaan lingkungan dan jenis makanan yang tersedia pada suatu lokasi. Hal ini sesuai dengan pernyataan (Alikodra, 1998) yang menyebutkan bahwa kualitas dan kuantitas suatu habitat akan menentukan komposisi, penyebaran, dan produktivitas organisme.

Indeks kemerataan jenis (e) dipengaruhi oleh besarnya nilai keanekaragaman suatu jenis dan jumlah seluruh jenis, artinya semakin tinggi nilai kelimpahan jenis maka penyebaran suatu jenis semakin merata dalam suatu kawasan tersebut. Menurut

(Odum, 1993), indeks kemerataan jenis (e) berkisar antara $0-1$, jika e $>1$ maka seluruh jenis yang ada memiliki kelimpahan yang sama atau merata, sedangkan jika e $<1$, maka seluruh jenis yang ada kelimpahan nya tidak merata. Berdasarkan hasil pengolahan data maka diketahui bahwa ternyata kemerataan antar jenis pada kelima hutan relatif hampir sama. Nilai indeks kemerataan pada habitat hutan dipterocarpaceae adalah sebesar e $=0,94$, hutan rawa gambut $\mathrm{e}=0,96$, hutan lahan basah terbuka/dataran terbuka e $=0,90$, hutan kerangas e $=0,98$, hutan riparian $\mathrm{e}=$ 0,80. Berdasarkan pengolahan data tersebut diketahui kemerataan yang paling tinggi terdapat pada habitat hutan kerangas yaitu sebesar $\mathrm{e}=0,98$ dan indeks kemerataan yang terendah ada pada habitat hutan riparian yaitu sebesar e $=0,80$. Hal ini menunjukkan bahwa kemerataan komunitas pada hutan PT. Hutan Ketapang Industri memiliki kemerataan yang merata. Hal ini disebabkan karena pada lima tipe habitat tersebut hampir memiliki tipe vegetasi yang hampir sama dan juga memiliki sumber pakan yang mencukupi bagi tiap-tiap spesies mamalia.

\section{Kesimpulan}

Berdasarkan hasil pengamatan yang dilakukan di lima tipe hutan PT. Hutan Ketapang Industri Kecamatan Kendawangan Kabupaten Ketapang jumlah mamalia diurnal yang berhasil diamati sebanyak 5 ordo, 6 famili, dan 8 spesies yang terdiri dari 61 individu. Hutan kerangas di jumpai sebanyak 2 jenis dengan jumlah individu 7 , hutan rawa 
gambut di jumpai sebanyak 5 jenis dengan jumlah individu 15, hutan dipterocarpaceae dataran rendah di jumpai sebanyak 7 jenis dengan individu 19, hutan riparian di jumpai sebanyak 3 jenis dengan jumlah individu 9, dan lahan basah terbuka/dataran banjir di jumpai sebanyak 3 jenis dengan jumlah individu 11 . Keanekaragaman jenis mamalia diurnal yang tertinggi terdapat pada area hutan dipterocarpaceae dengan nilai $(\bar{H})=0,79$. Hal ini dikarenakan jumlah individu yang ditemukan pada tiap hutan sedikit, hal tersebut dikarenakan pada saat penelitian banyaknya kegiatan manusia yaitu seperti menebang pohon.

\section{Saran}

Terdapat beberapa jenis mamalia yang dilindungi pada kawasan PT. Hutan Ketapang Industri maka perlu untuk menjaga kelestarian nya supaya tidak menjadi punah dengan cara melarang perburuan pada mamalia yang dilindungi dan memperjual belikannya.

\section{Ucapan Terima Kasih}

Penulis mengucapkan terima kasih banyak kepada pihak Enviro terutama Bapak James Simatupang selaku Manager Enviro yang telah bersedia memberi kesempatan penulis untul melakukan penelitian di wilayah PT. Hutan Ketapang
Industri, terima kasih kepada anggota Enviro yang bersedia membantu penulis untuk menyelesaikan penelitian ini terutama kepada Bapak Rendi, Aji, Fahri, Wegi, Yuni, Yeni dan bang Bonga (2009)

\section{DAFTAR PUSTAKA}

Anonim, 1998. Ensiklopedia Indonesia. Seri Fauna Mamalia, PT. Dai Nippon Printing Indonesia, Jakarta.

Alikodra, H S. 1998. Dasar-dasar pengelolaan habitat, proyek pendidikan dan latihan pengatur KSDA, Bogor.

Ferianita FM. 2007. Metode Sampling Bioekologi. PT. Bumi Aksara, Yogyakarta.

IUCN. Red List Categories and Criteria Version 3.1 Second Edition

Odum, EP. 1993. Dasar-dasar Ekologi.Edisi ketiga.Gadjah Mada University Press.Yogyakarta.

Bappenas 2003. Strategi dan Rencana Aksi Keanekaragaman Hayati Indonesia 2003-2020. Badan Perencanaan Pembangunan Nasional. Jakarta.

Suryanto, A. Semiadi. 2004. Keragaman Mamalia di Sekitar Daerah Penyangga Taman Nasional Gunung Halimun, Kecamatan Cipanas, Kabupaten Lebak. Berita Biologi 7(1): 87-94. 